\title{
Implications of Women leadership development with respect to Feminism
}

\author{
Hira Toheed \\ PhD Scholar \\ Bahria University, Islamabad, Pakistan \\ Jamshid Turi \\ PhD Scholar \\ Faculty of Industrial Management, \\ University Malaysia Pahang, Malaysia \\ Wardah Ali \\ PhD Scholar \\ Lincoln University, NewZealanad
}

\begin{abstract}
This paper is anticipated to examine the role of global feminism and gender stereotype behavior on women's leadership development. Moreover, the present research is accentuating to shed light on how global feminism and gender stereotypes have affected the female employees work life generally, and leaders especially. This study is aimed to analyze the current status of women's leadership development, and to investigate how to improve it in future. Women have always been an unsung hero of the society and stereotyping hinders women's career progression over the globe. The study selected 15 female leaders from various sectors, I.E, (education, media, medical, and NGOs) from Islamabad. The present study followed the inductive research approach through semi-structure interviews. The study divulges that leadership does not confine in the cage of gender stereotyping. The study shows that it is right time to remove such barriers from the society giving everyone equal opportunity to lead and achieve outstanding organizational performance. The study has significant implications towards mainstreaming women leaders in every walk of life. This research will enhance the digging of knowledge, skills and wisdom in women generally and of Pakistani women specifically.
\end{abstract}

Keywords: Global Feminism, Women Leadership development, Gender Stereotypes, Gender Inequality, women's career, women's leader progression, Gender, Leadership

\section{INTRODUCTION}

The general population is increasing with fast rate and same is true for women. The women proportion is increasing and women are making $50 \%$ of the total population. Now it is gaining attention and researchers and scholars are focusing to explore and probe this under investigated arena. Although a number of working women and leadership is growing yet in spite of the surface of eagerness, the records of female in the topmost leadership echelons at most companies are still thin all over the world (Madsen \& Andrade, 2018). Although 100s of documents have been written to create the awareness and significance of women leadership in the way of any nation's success sde by side with male leadership (Madsen, 2017). In the past, 'leadership' was supposed to be a dirty word for women in general and working women in particularly all over the world (Coates, 2015). Since long, women have been underestimated for their leadership qualities in many professions around the globe. They have not been 
considered more than a mark of domestic helper or labor only and in many parts of the world, they are not treated more than a slave (Anker, 1998). However, with the passage of time, a consecutive emphasis was developed in respect of exploring the skills and wisdom in women and women are visible in all walks of life all over the world including developing countries (Wise \& Wright, 2012).

In this regard, Gender stereotyping was considered to be the main hurdle or threat to women's leadership roles in organizations. It is believed that with the emerging role of global feminism, women have been able to accept and challenge this status quo (Timoshkina, 2008). Women have always been an unsung hero of the society and stereotyped as minority of the total population anywhere. Prior research reveals that training, workshops or seminars conducted on emphasizing the concept of feminism and anti-stereotypes can help women to oppose gender inequality among women and leaders (Stamarski \& Son Hing, 2015). The world is changing and does the women and the current statistics show that women leaders in the USA are occupying $40 \%$ of managerial positions approximately but before the feminist movement, they were as rare as hen's teeth (Eagly \& Carli, 2007). Similarly, in the European countries, EU, the board position of women has been inflated by $12 \%$ in 2010 to $23 \%$ in 2016, which is a remarkable achievement (Fritz \& van Knippenberg, 2017). As far as developing economies like Pakistan is concerned, the ratio of women's leadership is low due to the patriarchal and masculine culture. Although $50 \%$ of Pakistan's population consists of women yet they are not visible enough in corporate environment (Husain, Gater, Tomenson, \& Creed, 2004). It is revealed that in spite of female rising literacy rate in Pakistan, it is the top second having highest level of gender stereotypes in the world (Moin, Fatima, \& Qadir, 2018). This rising literacy rates helped in minimizing the concept of gender stereotypes and gender inequalities in leading professional positions. Alternatively, increasing the mode of counter-stereotypes can preserve and even increase to develop leadership among women development in women (Saramäki et al., 2014). Still there are more efforts required to eliminate or minimize the concept of patriarchal and gender stereotypes completely on a global level.

Past research has mixed views about women leaders and leadership. Few think that women can work under the leadership of men only, whereas Global feminist theorists say 'equality and equity concept' must be utilized to eradicate social injustice towards women employees and leaders (McCann \& Kim, 2013). In many parts of the world, women's leadership development is rising due to strategic management trainings and coaching that can shape women into successful mentors and leaders, still there are some loopholes to be filled in. Although numerous respondents were considered to fill the gap of generalizability of sample in the last research (Khalid, Muqadas, \& Rehman, 2017).

However, only emphasizing the advancement of women, mainly in some progressing countries will not be enough. Therefore, conducting a survey in a developing country like Pakistan where women's leadership development is not less than a challenge to prove their competency with a traditional burden of household chores will be invaluable (Bianco, Lombe, \& Bolis, 2017). Hence, this research will focus on the two vital factors, i.e., global feminism and gender stereotypes and their influence on women's leadership development generally and especially in developing economies like Pakistan with the mediating effect of women's working experience. Many studies have been conducted on women leadership in Pakistan in the past; however, there is still a need of creating awareness among conservative minds of Asian society that talent and leadership skills need no gender and cultural boundaries. The study will be a powerful tool for the management in devising equality and equity for all the races and genders that fosters high productivity of organizations in the future. Previously, feminism impact had not been not analyzed with respect to women leaders in Pakistan. 


\section{Gender Stereotypes}

\section{LITERATURE REVIEW}

Gender comprises of masculinity or femininity ratio as a distinctive characteristics consisting of different identities, providing individuals a sense of ownership; obeying social rituals and norms of the society \{Leicht, 2017 \#50\}). On the other hand, stereotypes has been clearly defined as the characteristics or traits associated with a specific group on the basis of gender, race, age, sect, religion or any other school of thought (Crites, Dickson, \& Lorenz, 2015). Gender stereotypes state the mind set of people related to each gender. They make some assumptions and associate qualities/ jobs done by each gender and do not agree to change this concept e.g., in developing and patriarchal societies like Pakistan, a common stereotype associated with women is that they are domestic workers and cannot success in career or professional fields. Several past studies has emphasized gender identification of women separately while working on gender and performance (Kaiser \& Hagiwara, 2011). However, in few studies, it was analyzed that Feminist approach must be related to women leadership characteristics through two different ways: one is under the influence of counter stereotypes. Second is under the conditions of high feminist identification (Leicht, Gocłowska, Van Breen, de Lemus, \& Randsley de Moura, 2017).

Many research scholars tried to explain literature to identify the status of women in relation to their gender identification. This theory paved way towards feminism and differentiated normal women from those women who believe in feminist school of thought. These are two separate social identities and psychological concepts (Roy, Weibust, \& Miller, 2007). Exploring these findings, it was found that women's reaction to gender stereotypes is much different than feminist's approach towards gender stereotypes. Women with a Feminists school of thought are not resistant to gender stereotypes. This effect was quite similar to those of high status independent, self-made women who are leaders, entrepreneurs or mentors (Gupta, Turban, \& Bhawe, 2008). If the world is supporting equal human rights then it would not be wrong to accept feminist approach too. Similarly, women in top management positions who have authority to lead an organization solely and instruct their team to achieve targets (Hoyt \& Blascovich, 2007). A fundamental theory in this regard is performativity theory (Butler, 2015). This theory challenged classified paradigms of gender, prescribing that gender is established and re-established through stereotypes school of thought and gender norms (Jenkins \& Finneman, 2018).

\section{Global Feminism}

The concept of global feminism is not much common. It is a newly derived term midway through the second decade of the twenty-first century, gender-based challenges were noticeable more (Madsen \& Scribner, 2017). Few researchers highlighted the fact that gender equality appears to be at the forefront of the global humanitarian grounds (Code, 2002). It is the need of the hour not to prove the competency and capability of women solely but to make the perception of the world at the right place for the concept of feminism. Over the last fifty years of history, vibrant and bold concepts about women's role in society and workplace have been introduced (Bartlett \& Henderson, 2013). Feminism is one of the most modern concepts describing liberation, equality, empowerment and participation (Batliwala, 2010). Theoretical approach towards feminism and globalization is typically an umbrella term which depicts the recent challenges; the world is facing at present. Such approaches involve various types of feminist theories like transactional feminists, postcolonial feminists and those feminists who believe in ethical power to accomplish any work (Bank, 2011). Feminist theory has sought to understand the way in which systemic or pervasive political and cultural structures are enacted and reproduced through individual acts and practices, and how the analysis of 
ostensibly personal situations is clarified through situating the issues in a broader and shared cultural context (Eagly \& Carli, 2007).

Impact of globalization on women has been observed as a mixed feature (Walby, 2005). An important piece of globalization is free trade markets, export processing and mutual sharing of commerce, trade, import, export and profits on global levels. Similarly, concepts for freedom of human beings, human thoughts and individual freedom have also been wide spread due to global connectivity (Cavanagh \& Mander, 2004). If western countries are following a campaign of gender equality then eastern countries must also be aware of feminist movement and gender counter stereotype movements around the world. No doubt globalization has put a landmark on awareness of human rights in every corner of the world (Moghadam, 2003). Due to these human rights movements around the globe, gulf countries have also started job positions for women ensuring that women have an equal and important role in public administration (Metcalfe, 2007). However, social media has also played an important role for the awareness campaign of feminism at international level. Globalization reveals the salient features of digital and social media as the most powerful tool for feminist school of thought. (Jackson, 2018).

\section{Working Experience}

It would not be wrong to say that mediating roles are important as they act as a bridge or ladder to find out the cause and effect relationship between two variables. Hence, education, upbringing and experience are the basic mediators that have enhanced women's role in top leadership positions from ancient times (Astin, 1984). While considering the scarcity of women's leaders in every other country, it may also be focused that capability or competency level of these women are up to the mark (Nussbaum, 2001). Saturation occurs when system is unable to provide quality required. Hence, it is very necessary that in order to obtain a successful position as men, a feminist leader must have spent a part of her life in learning and experience. Only developments and programs to train them to be leaders would not be enough. (Ibarra \& Obodaru, 2009). It is stated that there are specific leadership qualities which are seen only after a specific number of years spent in a career. For a career oriented women, this route to a successful leader be comparatively easy as compared compare to the one without any know how, of knowledge and skills (Bailyn, 1993). However, few studies argue that experience only cannot be attached as a key to success because demographic characteristics are tested to have not a significant impact on successful leadership approaches, e.g., background, ethnicity, working experience, education, marital status etc. (Belias, Gkolia, Koustelios, \& Varsanis, 2015).

\section{Women Leadership Development}

It is quite useful to know that the perspective on gender and leadership approach surely called for a new development agenda and ultimately paving the way towards women leadership positions (Ely, Ibarra, \& Kolb, 2011). It is evident that society stereotypes for genders have high impact on women's ability to be a successful leader. Theories suggest that constituting and adopting the identity or characteristics of a leader is the first step to become a leader (Scott DeRue \& Ashford, 2010), but due to gender bias behavior from surrounding, mostly women could not recognize leadership qualities within themselves and the result is selfexplanatory: Underrepresentation and low statistics of Women in leaders' roles is due to deep rooted systems and ancient mind set of people which in turn cannot challenge the status quo and supports men's bid for leadership (Ibarra \& Petriglieri, 2010). However, some researchers argue and believe on revolution that Women must learn leadership roles irrespective of the gender biasness they face through leadership development programs, trainings and workshops. These trainings can help in starting an awareness campaign about what senior and 
top leading roles women can perform successfully. Such developments may help women in identifying their careers more wisely adding a valuable mark in their portfolio (Ely et al., 2011).

Furthermore, researchers have the perspective of feminist leadership also that can fortify the outputs of business in many sectors like corporate, governance, economics, human rights etc. He also explained that how transformative and feminist leadership are important in strengthening the business line of any country (Wakefield, 2017). History is the proof that women have contributed more than anything in the success and accounts of the firms worldwide (Durepos, McKinlay, \& Taylor, 2017). Therefore, underestimating a women's power will not be justified and judged until they are provided with the training programs that can enhance women leadership development at individual as well as at collective level.

\section{Research Design}

\section{METHODOLOGY}

Research design in this study was based on constructionist grounded theory approach as proposed by (Gibbs, 2007; Charmaz, 2006) which is based on the analysis of selected cases or individuals and generating theory. This method focuses the middle theories model to explore the possibility of generalizing it in future. This method is more popular in business research social sciences . research and middle range theories represent work in a limited domain (Bell \& Bryman, 2007).

\section{Research Approach}

The present study followed inductive research approach through semi-structure interviews. The in depth interviews method was used in order to discover in details the new dimensions of global feminism and women leadership development. (Campbell, Quincy, Osserman, \& Pedersen, 2013). The responses from the interviews were recorded, transcribed and coded in harmony with grounded theory methodology and using Nvivo 12 software. Encoding process was used for the identification of major arguments and ideas. Through an encoding process, major arguments and ideas were identified and registered. The mode of every interview was face to face. Data were recorded, transcribed, and analyzed thematically.

\section{Sample size and Sampling technique}

Since, this study is mainly based on successful women leaders, hence interviews of 15 women were targeted but three of them did not response and hence the study was restricted with 12 interviews. The respondents' women leaders were chosen from various sectors, i.e., NGOs (03) medical (04), education (07), social services (01) who had more than 10 years of work experience. All respondents were above 30 years of age. The respondents brief profile is explained in table-1

\section{Gender biasness and work experience}

\section{ANALYSIS AND FINDINGS}

The respondents were divided into 03 groups they quote. The first group $(N=5)$ responded that they faced a lot of criticism, gender biasness and politics just for being a woman. The statement from first group reflected that "I have faced a lot of biasness on the basis of religion and gender as well". Second group was agreed on the fact that they enjoyed their job throughout. It was a positive experience for them $(\mathrm{N}=3)$ and only 03 respondents were confused to decide whether the statement of favourism and leg pulling during leadership work experience or not because they told it varies from organization to organization or industry to industry. For example, a respondent stated that "My work experience has been a kind of mixed". ( $\mathrm{N}=4)$. These comments reveal that Gender Stereotyping is commonly faced by women leaders and some stereotypes 
are seriously affected by it. These results are very much similar with the results of previous studies results which states that the commitment level of women are dragging their position and scope in the world more positively, irrespective of the odd norms of gender discrimination and society. (Oom-Dove, 2017). Result explains that out of twelve eight respondents were agreed that stereotypes were having negative effects women leaders and leadership roles, whereas only 2 were of the view that stereotypes played positive roles in leadership development. The one respondent said that stereotypes do not affect women leadership rather it is neutral.

Fig 1 Gender Stereotype - Word Tree

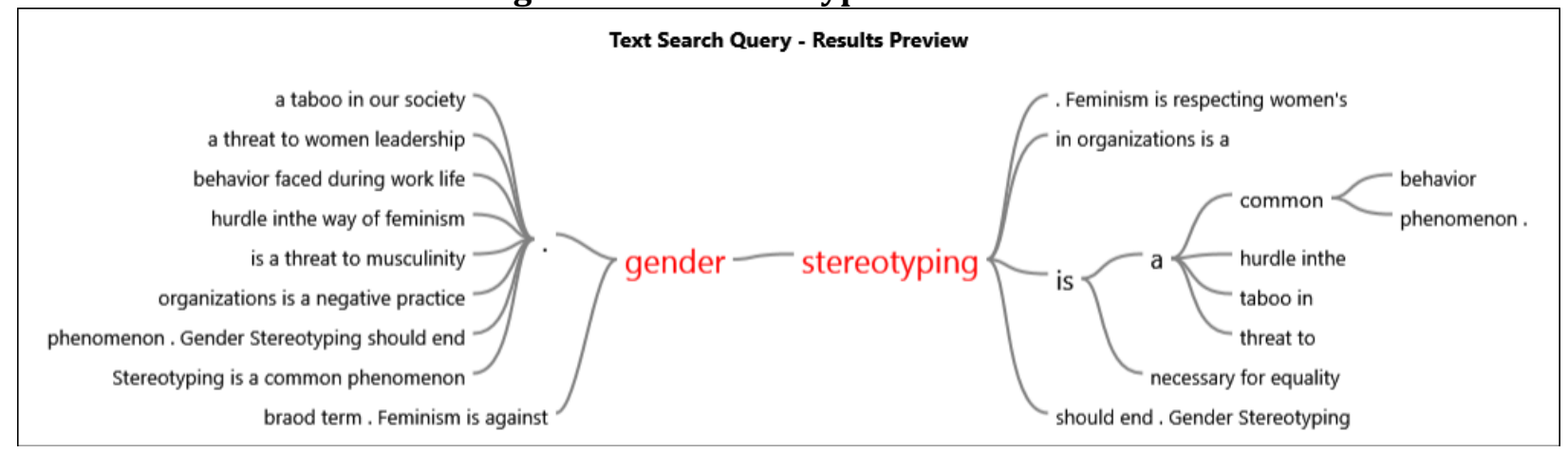

Figure 1 explains a word tree approach about gender stereotyping. Most respondents explained it as a taboo in the society, a threat to women leadership or a negative behavior faced during work life, an obstacle or unequal behaviors of people.

\section{Global Feminism is not the right path towards empowerment / leadership of women}

The respondents are divided into 03 groups based on the results. It is clearly shown that first group ( $\mathrm{N}=4)$ supported the new wave of global feminism as a powerful tool for women's rights. Second group communicated the fact that feminism is a project raised at international level launched just to break our rituals and practices for women since the time of our ancestors. This campaign will drag away the Pakistani women from their basic chores of house work and raising family and pushing them towards a robotic life of working women. $(\mathrm{N}=6)$ Whereas there was a third group of women leaders who have mixed views about feminism and they cannot identify whether this new theory will be helpful for the society or destructive in the long term $(\mathrm{N}=2)$. It is quite evident from this research that Pakistani people are still conservative and do not believe in supporting the wave of global feminism at any cost. Following tree and table will explain:

\section{Work Experience varies from industry to industry towards gender biasness}

Results show that work experience of every leader varies from industry to industry and situation to situation. Analysis show that approximately, half of them consider their work life as a great experience towards learning and development $(\mathrm{N}=6)$ whereas, the other half respondents $(\mathrm{N}=6)$ said it to be a tough fight for survival in male dominant society. One of the respondents said that "My work experience was kind of filled with problems at every step". They had to fight politics, bullying and sexual harassment throughout their careers. The following tables will clarify it more

\section{Women Leadership Development in Pakistan requires more awareness campaigns since the leadership has no gender}

The results depict that the chances of women's leadership development in Pakistan are positive if it is to be taken in the right direction. It will be worthy to capture the complication in 
achieving the levels of women's rights in the working environment $(\mathrm{N}=8)$. Table 5 shows that majority of respondents supporting the idea of launching awareness campaigns of women leadership development, and identifying it to be a key factors towards the progress of a country from less developmentally to grow. One of the women leaders said that "Women leadership can only be enhanced if women will feel safe". Whereas, $\mathrm{N}=2$ respondents were confused about whether such trainings and sessions will be worthy or not. Since $\mathrm{N}=2$ were not in the favor of any such development in the future because of the negative attitudes they have faced in their careers.

\section{Leadership has no gender or size, it's all about knowledge, wisdom and talent}

The crux of the communication from mostly women leaders leaded to the fact that leadership is not dependable on the gender, race or ethnicity. It is about talent, skills and vision of a mind towards progress and leading the team in the right direction. Its high time that we may acknowledge skills and talent instead of appearance and looks. Maybe a transgender is the stronger leader instead of a man or woman leader considered by the society. It is the time that people must change their vision to see things and work only for the progress of country. This is possible only if we as a nation take stand to support our woman and other genders to take part in the professional working environment. Talent must not be confined to a home only. It must break the barriers. In this regard, whatever development campaigns can be launched, they must be supported by govt and normal people. Only then Pakistan as a nation can be strengthened.

\section{CONCLUSION}

In this paper, the relationship between global feminism, gender stereotypes and women's leadership is explored. The results revealed that there is nothing wrong with a woman, if she wants to run her house, to be a successful leader and she wants to win in every field of life. People should clear their mindset and misconception that women leaders cannot handle organizations successfully. In the past, women leaders have proven it that they can lead in all walks of life and there are many incidents to support this. We are living in the 21st century with the global transformation in every field from simple mechanism to state of the art technology. It is no longer feasible to attach taboos, customs, norms and past practices with respect to organizational performance. It is a common perception in developing economies like Pakistan that only men leaders are successful as they pay full attention towards the work. However, this is a myth yet to prove, hence, it is needed to involve all including women without any partiality. To make use of talent, skills, and experience without going into gender. It is the time to bring women in mainstreaming and they may be given leadership roles.

Leadership is a broad phenomenon which states that the leadership has no boundaries to explore and unearth talent. Leadership is the name of capabilities and abilities whosoever is capable must be given a chance to lead irrespective of ethnicity, gender or race. As a result hybrid leadership will prevail and organizations will be more benefited from make female leadership and attain success.

In this article, we offer a framework for women's leadership development grounded in theories of both gender and leadership. The findings of this research suggest that it will be an important step in breaking the ice. One thing is sure to be concluded that Leadership has no gender; it only knows knowledge skills and attitude of a person. Another important challenge can be to create awareness among organizational people understand the fact that it's high time to challenge the status quo and breaking the glass ceiling by promoting their women to come forward and lead. There is no harm or embarrassment in it. We conceptualize leadership development as identity work and show how subtle forms of gender bias in the culture and in 
organizations interfere with the identity work of women leaders. This perspective on gender and leadership calls for a new developmental agenda for women in, and aspiring to, leadership roles.

\section{LIMITATIONS \& FUTURE DIRECTIONS}

Further studies are recommended since data was collected from 15 women leaders only; hence the results cannot be applied on generalized. Large data and other areas of Pakistan or any other country must be included in the future study. Similarly, Further studies on such controversial and sensitive topics are required to create awareness among organizations and normal people of a less developed country like Pakistan that women are not born for their slavery or house chores, they have a complete right to prove their talent in any professional field and the people must support them. Furthermore, exploration of feminist theory approach and how it implies in organizations with respect to women's leadership is important. As far as Pakistani society is concerned, most people are conservative and support non-working women just used as labors at home for their own personal work. No one support women empowerment and freedom of women rights. It is kind of a tough struggle to change the stereotypical behavior of common man towards the genuine rights of women. Future research will allow better adjustments and consequences to introduce the impact of feminism on women leaders, their vision and their long term goals. Future research could be on the interrelationship between dimensions of feminism and different types of women leadership, i.e., transformative, feminist or servant, etc. which will help in enhancing the clarity between their relationships and enlightening more angles from it.

\section{IMPLICATIONS}

First and foremost implication of this study is that organizations must realize the importance of talent and skills instead of gender. The common concept of "leaders can be only men" should be eliminated now.

Industries like medical sections always require female doctors, as female patients prefer to consult them. Similarly, social mobilization is one of the areas which needs to encourage female leaders. This view can be more strengthened in the eyes of people. This study implies that more campaigns, seminars and lectures must be arranged in order to break the glass ceiling and giving our women a priority in professional fields. Centering the women as leaders through the lens of feminist practices and theoretical framework are much needed to make women more noticeable (Drucza \& Peveri, 2018). Women's Rights movement in Pakistan has been too long as women have always been the unsung heroes of the society. To credit and honor them for their phenomenal contributions as an individual and as a team member, it is important to notice them and regard them, Increased economic opportunities and alterations in the social vision, it is required that women must be provided access of finance and moral support to prove their talent and rise from a small scale to a large scale. It is not hidden that an increasing number of young and old women are struggling to enter the workforce and working hand in hand along with men. It is our duty to respect their interest, vision and participation in every field of the professional world making an equal opportunity for employees.

\section{References}

Acker, J. (2005). Class questions: Feminist answers: AltaMira Press.

Astin, H. S. (1984). The Meaning of Work in Women's Lives A Sociopsychological Model of Career Choice and Work Behavior. The counseling psychologist, 12(4), 117-126.

Bailyn, L. (1993). Breaking the mold: Women, men, and time in the new corporate world: Simon and Schuster.

Bank, B. J. (2011). Gender and higher education: JHU Press. 
Bartlett, A., \& Henderson, M. (2013). The Australian women's movement goes to the museum: The 'cultures of Australian feminist activism, 1970-1990'project. Paper presented at the Women's Studies International Forum.

Batliwala, S. (2010). Feminist leadership for social transformation: Clearing the conceptual cloud. New Delhi: Creating Resources for Empowerment in Action.

Belias, D., Gkolia, A., Koustelios, A., \& Varsanis, K. (2015). Leadership style and personal characteristics of Greek banking employees. Journal of Management Research, 15(3), 156-164.

Bell, E., \& Bryman, A. (2007). The ethics of management research: an exploratory content analysis. British Journal of Management, 18(1), 63-77.

Butler, J. (2015). Notes toward a performative theory of assembly: Harvard University Press.

Campbell, J. L., Quincy, C., Osserman, J., \& Pedersen, O. K. (2013). Coding in-depth semistructured interviews: Problems of unitization and intercoder reliability and agreement. Sociological Methods \& Research, 42(3), 294320 .

Cavanagh, J., \& Mander, J. (2004). Alternatives to economic globalization: A better world is possible: BerrettKoehler Publishers.

Coates, J. (2015). Women, men and language: A sociolinguistic account of gender differences in language: Routledge.

Code, L. (2002). Encyclopedia of feminist theories: Routledge.

Crites, S. N., Dickson, K. E., \& Lorenz, A. (2015). Nurturing gender stereotypes in the face of experience: A study of leader gender, leadership style, and satisfaction. Journal of Organizational Culture, Communications and Conflict, $19(1), 1$.

Drucza, K., \& Peveri, V. (2018). Literature on gendered agriculture in Pakistan: Neglect of women's contributions. Paper presented at the Women's Studies International Forum.

Durepos, G., McKinlay, A., \& Taylor, S. (2017). Narrating histories of women at work: Archives, stories, and the promise of feminism. Business History, 59(8), 1261-1279.

Ely, R. J., Ibarra, H., \& Kolb, D. M. (2011). Taking gender into account: Theory and design for women's leadership development programs. Academy of Management Learning \& Education, 10(3), 474-493.

Gupta, V. K., Turban, D. B., \& Bhawe, N. M. (2008). The effect of gender stereotype activation on entrepreneurial intentions. Journal of applied psychology, 93(5), 1053.

Hoyt, C. L., \& Blascovich, J. (2007). Leadership efficacy and women leaders' responses to stereotype activation. Group Processes \& Intergroup Relations, 10(4), 595-616.

Husain, N., Gater, R., Tomenson, B., \& Creed, F. (2004). Social factors associated with chronic depression among a population-based sample of women in rural Pakistan. Social Psychiatry and Psychiatric Epidemiology, 39(8), 618624.

Ibarra, H., \& Petriglieri, J. L. (2010). Identity work and play. Journal of Organizational Change Management, 23(1), 10-25.

Jackson, S. (2018). Young feminists, feminism and digital media. Feminism \& Psychology, 28(1), 32-49.

Jenkins, J., \& Finneman, T. (2018). Gender trouble in the workplace: applying Judith Butler's theory of performativity to news organizations. Feminist Media Studies, 18(2), 157-172.

Kaiser, C. R., \& Hagiwara, N. (2011). Gender identification moderates social identity threat effects on working memory. Psychology of Women Quarterly, 35(2), 243-251.

Leicht, C., Gocłowska, M. A., Van Breen, J. A., de Lemus, S., \& Randsley de Moura, G. (2017). Counter-stereotypes and feminism promote leadership aspirations in highly identified women. Frontiers in psychology, 8, 883.

Madsen, S. R. (2017). Handbook of Research on Gender and Leadership: Edward Elgar Publishing.

Madsen, S. R., \& Andrade, M. S. (2018). Unconscious Gender Bias: Implications for Women's Leadership Development. Journal of Leadership Studies.

Madsen, S. R., \& Scribner, R. T. (2017). A perspective on gender in management: The need for strategic crosscultural scholarship on women in management and leadership. Cross Cultural \& Strategic Management, 24(2), 231-250. 
Moghadam, V. M. (2003). Modernizing women: Gender and social change in the Middle East: Lynne Rienner Publishers.

Nussbaum, M. C. (2001). Women and human development: The capabilities approach (Vol. 3): Cambridge University Press.

Oom-Dove, S. A. (2017). Revivalist women's submission: Women's spiritual authority, biblical feminism and cosmofeminism. Paper presented at the Women's Studies International Forum.

Roy, R. E., Weibust, K. S., \& Miller, C. T. (2007). Effects of stereotypes about feminists on feminist selfidentification. Psychology of Women Quarterly, 31(2), 146-156.

Scott DeRue, D., \& Ashford, S. J. (2010). Power to the people: Where has personal agency gone in leadership development? Industrial and Organizational Psychology, 3(1), 24-27.

Stamarski, C. S., \& Son Hing, L. S. (2015). Gender inequalities in the workplace: the effects of organizational structures, processes, practices, and decision makers' sexism. Frontiers in psychology, 6, 1400.

Timoshkina, N. (2008). Non-hierarchical organizing and international women's NGOs: An exploratory study: University of Toronto Toronto, Canada.

Wakefield, S. (2017). Transformative and Feminist Leadership for Women's Rights: Boston, Oxfam. Retrieved from https://www. oxfamamerica. org/explore/research-publications/transformativefeministleadership-womensrights.

Wise, V., \& Wright, T. (2012). Critical Absence in the Field of Educational Administration: Framing the (Missing) Discourse of Leadership in Early Childhood Settings. International Journal of Educational Leadership Preparation, $7(2), \mathrm{n} 2$.

Zuckerman, E., Orgocka, A., Poe, J., \& Feldstein, H. S. (2005). Reforming the World Bank: Will the Gender Strategy Make a Difference? 